\title{
KNOWLEDGE MANAGEMENT IN THE CONSTRUCTION INDUSTRY: CURRENT STATE OF KNOWLEDGE AND FUTURE RESEARCH
}

\author{
Víctor YEPES ${ }^{*}$, Salvador LÓPEZ $\mathbb{B}$ \\ ICITECH, Department of Construction Engineering, Universitat Politècnica de València, 46022 Valencia, Spain
}

Received 15 December 2020; accepted 16 November 2021

\begin{abstract}
Knowledge management in the construction industry has become an element of transition between traditional processes and the current needs demanded by technological change. This research reviews the updated scientific contributions of knowledge management in construction, as well as its influence. The results come from a bibliometric study, elaborating a quantitative and qualitative analysis of the current state. The research method was divided into the following stages: preliminary approach to the bibliography, establishment of search strategies, selection and classification of articles, quantitative analysis and discussion of relevant articles. Three main factors were identified: use and exploitation of knowledge, knowledge transfer, and information technologies; five complementary facets were also identified: culture, innovation, quality, knowledge generation and human factors. The results reaffirm the importance of the use and exploitation of knowledge, in addition to increasing attention to the transfer and technology of information. However, the generation of knowledge has declined because the sector still does not report the results of applying knowledge, and this underlines the need for the future study of strategies to transform tacit knowledge into explicit knowledge.
\end{abstract}

Keywords: knowledge management, state of knowledge, bibliometric analysis, construction industry, use and exploitation of knowledge, knowledge transfer.

\section{Introduction}

Knowledge management has become an indispensable intellectual asset in obtaining a competitive advantage (Yang et al., 2014; Yu \& Yang, 2018), and should be considered a key element of good practice in an organization. As a systematic, integrated and directed process (Arriagada \& Alarcón, 2014), it allows the balance between the use of technology, human relations and strategic management. The purpose of this study is to determine the current state of investigation in knowledge management in the construction sector, from 2012 to date, complementing the paper of Castro et al. (2012).

Knowledge is a product of learning (Qian $\mathrm{Li}$ et al., 2017) that allows employees to act and make better decisions, becoming in the long term an added value. It has always been considered an abstract concept, associated with intangible assets (Hartono et al., 2019), a main challenge being the management of knowledge assets (Hoła et al., 2015), which is the core of knowledge management (Castillo et al., 2018). The more knowledge remains tacit, the more difficult its management is (Zhang \& He, 2016). On the contrary, if it becomes explicit, it improves the process (Senaratne et al., 2017) of its management (Sun et al., 2019).

In the last decades, research, in addition to increasing the evaluation of social impacts (Navarro et al., 2020), has emphasized the complexity of the processes used in the construction industry (Villarreal et al., 2017), because the sector intensively combines knowledge and experience (Yang et al., 2014). The problem is not the generation of knowledge in the construction sector, but the waste of valuable information for future projects (Alashwal \& Abdul-Rahman, 2014b). Therefore, building on previous knowledge transforms beliefs and previous patterns (Pellicer et al., 2012), from which it can be concluded that the more capabilities an organization has, the greater will be its adaptation to technological changes (Papadonikolaki, 2018).

With the demand for qualified personnel, the globalization of the economy and the presence of technological change in all areas, the professional development of staff is also changing. The challenge is to develop talent (Junyong, 2018), because it is people who have the knowledge.

*Corresponding author. E-mail: vyepesp@cst.upv.es 
Only through the periodic evaluation of entrepreneurship, knowledge sharing, organizational learning and the improvement of social capital (Senaratne et al., 2017) is it possible to improve the stock of knowledge and employees' skills, in addition to improving organizational and innovative performance ( $\mathrm{Ni}$ et al., 2018).

The construction sector should take initiatives to develop a knowledge culture (Zhang \& Ng, 2012b), not only to manage time threats, costs (Ortiz-González et al., 2018) and poorly managed projects (Orsi et al., 2020), but also to generate opportunities to renew knowledge. The measures of openness (Kale \& Karaman, 2012b) and flexibility (Zhu \& Cheung, 2017) generate confidence, which is a very important factor, affecting both those who seek and those who generate knowledge (Arif et al., 2015). Finally, inefficiency can be reversed by transmitting, expanding and renewing knowledge in the presence of technological change (Papadonikolaki, 2018), benefiting the organization (Eken et al., 2020) in the long term.

Hence, this study set to answer two questions: what has been studied from 2012 to 2020 in regard to knowledge management in construction? and what are the potential research directions in the future? To answer these questions, major topics and research framework were summarized, and future research directions were predicted in this paper on the basis of literature review.

The remainder of this article is organized as follows. The literature retrieval methodology and paper selection is explained in Materials and methods section. The past research framework is summarized in Literature review section, through eight subchapters. The Prediction section proposes the prediction of possible research directions to improve the past research framework. Finally, conclusions, limitations and future work are presented in the Conclusions section.

\section{Literature review}

Knowledge management is a systematic, organized (Liu et al., 2019) and continuous (Kim, 2014) process, whose objectives are to increase competitiveness, promote organizational learning and preserve knowledge. It is applied throughout the organization, adapting to policies and always requiring monitoring and evaluation. Good knowledge management becomes a competitive strategy (Ni et al., 2018), because it works on learning from previous lessons, avoiding mistakes and repeating successes (Dong et al., 2018).

It is based on three pillars, which are technology, human relations and strategic management (Arriagada \& Alarcón, 2014), its effectiveness being determined based on the balance between them: technology, focused on the creation and reuse of knowledge; human relations, interested in creating qualified networks; and strategic management, focused on the optimal use of intellectual capacities.

In the research of Pellicer et al. (2011), they conceive knowledge management as fundamental for the feedback processes of quality and innovation management in com- panies (see Figure 1). Likewise, for this paper we will use the classification made in the paper of Castro et al. (2012) to delimit it, consisting of: knowledge culture, human factors, quality of information, generation of knowledge, knowledge transfer, use and exploitation of knowledge, innovation and, finally, information and communication technologies.

Figure 2 shows the interrelationships between the eight factors of knowledge management. A solid line indicates a direct relationship between two factors, so that one factor directly influences the objective factor. In contrast, a dotted line indicates an indirect relationship between two factors. In this case, however, the relationship is not direct; that is, the source factor influences other factors that, in turn, influence the objective factor. These relationships are shown in Figure 2, resulting in a model that represents the influences between the knowledge management factors.

Knowledge management is made difficult when it is not known either what knowledge is held or what its potential use is (Caldas et al., 2015) and, like innovation in

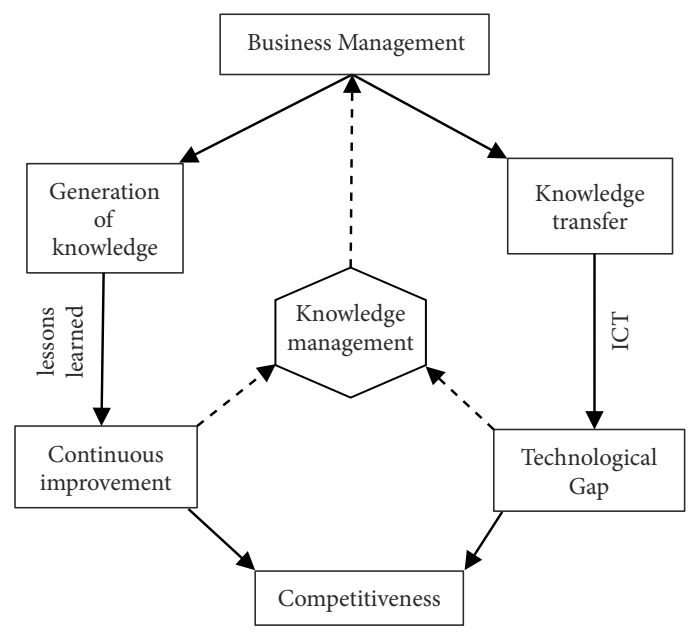

Figure 1. Quality, innovation, and knowledge relationships in firms

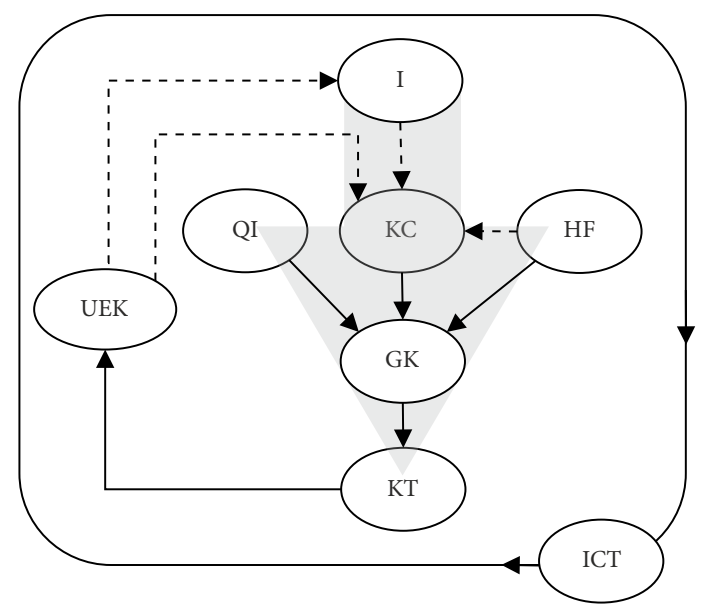

Innovation (I); Quality of Information (QI); Knowledge Culture (KC); Human Factors (HF); Use and Exploitation of Knowledge (UEK); Generation of Knowledge (GK);

Knowledge Transfer (KT); Information and Communication Technologies (ICT)

Figure 2. The knowledge management cycle in organizations 
the sector, it is considered a process that is not yet standardized (Yepes et al., 2016). Also, its good management can become a trigger that increases profits (Sun et al., 2019), because companies in the sector are very competitive and have small profit margins (Skibniewski \& Zavadskas, 2013).

After applying the respective criteria to update the state of the art to the current year, the articles considered most important were analyzed from both a quantitative and qualitative perspective, using the framework of Castro et al. (2012), represented in Figure 2. Subsequently, the resultant publications were classified into the eight aspects of the model adopted, and the researchers' contributions are summarized in the following section.

\subsection{Knowledge culture}

The culture of knowledge in organizations has become a key factor for knowledge transfer, provided that there is a constant flow of information. Knowledge is tied to individuals (Goddard et al., 2016), and this is why the main concern of organizations is the generation of an environment of social interaction to allow the flow of information. On the other hand, individuals must be provided with resources, continuous training, and the necessary strategies to apply knowledge in specific situations.

The establishment of a knowledge culture in the organization is influenced by the attitude of the employees. This represents a critical barrier to change, because inherited values and beliefs are not readily questioned (Vennström \& Eriksson, 2010), in addition to which there may be concern about being replaced in the job if knowledge is shared. However, it is possible to generate confidence in the organization (Arif et al., 2015) if horizontal leadership is consolidated in the organizational structure, which is the first step in developing the commitment (AlTmeemy et al., 2012), collaboration, and loyalty of the employees (Kale \& Karaman, 2012b).

\subsection{Human factors}

One of the main drivers of national economies are companies. As long as there is no reason to stop their activity, the companies will generate the offer and demand of heterogeneous human resources, maintaining personnel with more capacity and aptitude. Currently, human resources are indispensable to the organization, due to specific historical conditions, social complexity and causal ambiguity (Zhai et al., 2014).

The personnel are the main creators of functional knowledge (Ding et al., 2013) in an organization. From the human development perspective, there are two main aspects that potentialize people's capabilities, being personal motivations and contextual factors (Zhang \& Ng, 2013). In principle, personal motivations are developed based on trust (Zhang \& Ng, 2012a), tightly connected social networks and shared objectives. On the other hand, contextual factors, whose essence is centered on the orga- nizational climate, influence the behaviors, attitudes and prevailing norms (Yang \& Cheng, 2020). It is important to emphasize that personnel in pursuit of knowledge will always be connected through affinity with others. If that affinity is supported by the higher levels, then the importance of human factors in the exchange of knowledge is recognized.

\subsection{Quality of information}

The quality of information is defined, according to research of Sheriff et al. (2012), as a critical element for the innovation and optimal performance of companies. For this reason, construction companies that have implemented quality management systems, based on ISO 10006 in 2005 and ISO 9001 in 2008, have increased their efficiency, competitiveness (Hoła et al., 2015) and innovation capacity (Pellicer et al., 2014).

From a more entrepreneurial perspective, information quality is seen as a corporate asset that aligns information demands with business processes, improving the ability to run a business, its performance and operational efficiency (Sheriff et al., 2012). On the other hand, information quality requires constant rethinking and a holistic view. The first is to ensure long-term competitive advantage and the second is to balance both technologies and the capacity of staff to use and leverage information for more profitable results.

\subsection{Information and communication technologies}

Information and communication technologies constitute a technological infrastructure that facilitates the codification of knowledge to be placed in databases (Park et al., 2013), enabling its agile collection, storage and exchange (Kale \& Karaman, 2012a). In addition, it creates an interconnected environment that strengthens the volume of knowledge (Tan et al., 2012) coming from the construction process, departments and the work field.

The barriers limiting the potential represented by information technologies are a product of the fragmentation of the sector, i.e., the disconnection of personnel between departments continues to be an obstacle (Haron et al., 2015) to overcome. There is also a fear of data security, failures and a lack of knowledge about how to use platforms (Afolabi et al., 2017), and a lack of physical control.

Finally, they are evolving as a tool capable of dealing with more complex projects, promoting the use of more complex business systems (Afolabi et al., 2017), the efficiency and effectiveness (Nourbakhsh et al., 2012) of information exchange, remote access to administrative activities and web-based project management (Doloi, 2014). The ease of use and perceived usefulness, determine the behavioural intention to use a technology (Wang et al., 2020). This facilitates the transmission of information to human knowledge, which is one of the main tasks of knowledge sharing (H. Wang \& S. Wang, 2016). 


\subsection{Generation of knowledge}

The generation of knowledge is the extraction of knowledge from individuals or groups (Addis, 2016) with the purpose of collecting, renewing and codifying it, allowing its use at all organizational levels. It is an interconnected process that involves teams, individual skills (Alashwal \& Abdul-Rahman, 2014a) and organizational leaders, creating a network of relationships. It not only consists in the creation, but also implies the adaptation of existing knowledge (Kale \& Karaman, 2012a), for the benefit of corporate learning (Baloian \& Zurita, 2012). It comes from a combination of factors, beginning with everyday practice, informal dialogues among employees, and shared objectives.

Knowledge is represented as explicit and tacit. While explicit knowledge refers to that which can be stored and distributed, tacit knowledge belongs to the personnel of the organizations. Traditionally, explicit knowledge has been considered very important for managing new knowledge, which demeans tacit knowledge that is just as important. An important strategy will be to convert tacit knowledge into explicit knowledge (Baloian \& Zurita, 2012), relying on the use of tools and techniques (Yap \& Lock, 2017) to achieve the creation, storage and application of knowledge, which is the prelude to innovation.

\subsection{Knowledge transfer}

Knowledge transfer is defined as a social form in which individuals, teams and organizations interact (Keung \& Shen, 2013), to share a commitment with a common purpose. In research of Alashwal and Abdul-Rahman (2014b) it is defined as the flow of knowledge from a source to a receiver for assimilation and reuse, based on previous experience. On the other hand, Keung and Shen (2013) define it as a functional activity at an internal level, in which team members interact with each other, collecting and disseminating knowledge.

Knowledge is also represented from internal and external approaches. Internal knowledge is generated in the organization itself, coming from the personnel, the design processes (Bashouri \& Duncan, 2014) and the decision making, generally supported by the technical capacities, social dimension and culture of knowledge (Costa et al., 2016). External knowledge is generated in other organizations, and is more appreciated than internal knowledge, although both are equally important (Javernick-Will, 2012).

The purposes of knowledge transfer consist of the application, systematization (Arriagada \& Alarcón, 2014) and socialization of knowledge. Its application is to benefit the results of the project (Garcia \& Mollaoglu, 2020), to generate more value (Park et al., 2013), to encourage exchange within the organization and between organizations (Wu, 2013), and to avoid the loss of knowledge. Likewise, systematization represents the passage from the object to the routine (Arriagada \& Alarcón, 2014), and socialization means transmitting people's knowledge to the organization. It is the responsibility of managers to invest, motivate, and encourage human resources in a context of reciprocity and cultural identity (Schröpfer et al., 2017).

In the construction sector, other factors may be considered more important than the transfer of knowledge. First is delivery times, referring to the need to comply with the planning. Second is the organizational structure (Forcada et al., 2013), often considered by itself as too lean for the knowledge exploitation. Third is the organizational culture (Zhang \& He, 2016), which traditionally excludes long-term strategies. Then there is the maintenance of knowledge in the tacit context (Schröpfer et al., 2017), because it is neither demanded nor considered relevant. Finally, the transfer of knowledge will be unsuccessful if direct communication and trust fail (Sun et al., 2019), even within the same company (Javernick-Will, 2012), because it requires a certain level of shared meaning (Alashwal \& Abdul-Rahman, 2014b).

\subsection{Use and exploitation of knowledge}

The use and exploitation of knowledge is defined as the use of transferred knowledge that provides value to the organization (Alashwal et al., 2016), and is able to solve both human errors and technical problems, optimizing time in the project results and supporting decision making (Jansson et al., 2015). It should be treated as institutionalized learning capable of connecting personnel (Alashwal et al., 2016), that is, a methodical collection disposed in the transfer networks that can be assimilated by the workers (Kale \& Karaman, 2012b) and that is constructed on the basis of the articulation capacity of the sender of the knowledge (Garcia \& Mollaoglu, 2020). Depending on the articulation capacity of the emitter will be the absorption capacity of a recipient of knowledge, even if there is no common knowledge between them.

This is based on four principal phases known as: construction, incarnation, diffusion (Kale \& Karaman, 2012b) and use (Kim, 2014). Firstly, the construction phase is where the knowledge is structured. Secondly, it is in the incarnation phase that the site of the concentration of knowledge is chosen. Thirdly, the phase of dissemination makes the knowledge available. Finally, the stage of use is the result that gives value to the organization (Kim, 2014). In addition, the internal learning routines and the absorption capacity of the companies must be known in order to use it correctly; only in this way is it possible to update the traditional routines of the sector (Manley \& Chen, 2015).

Their principal deficiencies are linked to the lack of knowledge when it is required, the loss of important knowledge (Yap \& Lock, 2017), the repetition of previous efforts and the inability of workers to use the information. On the contrary, if we learn from the previous lessons, it will be possible to develop the potential for innovation in a company (Goddard et al., 2016).

\subsection{Innovation}

Innovation not only represents the creation of new things; that is, it can also be considered within the adoption, 
adaptation and modification of processes as well as the management and organization of work (Pellicer et al., 2012), as long as it generates alternatives in accordance with technological changes (Walker, 2016). It is considered an advanced activity, in both the scientific and technical aspects, that requires more complex communication processes (Lindgren et al., 2018). Being an advanced activity implies being holistic (Sujan et al., 2020), continuous, and systematic (Yepes et al., 2016), which means integrating both processes and people, thus eradicating the isolated perception of it.

Although it is an important part of the organization's management (Pellicer et al., 2017), innovation has the disadvantages that its processes are not completely understood (Lindgren et al., 2018), it is considered unnecessary in the short term (Castillo et al., 2018), and it does not have specific departments for its standardized management, all of which affect the potential benefits (Hadiwattege et al., 2018). On the other hand, it represents uncertainty (Kildienè et al., 2014) when it is adopted, although this can be mitigated through standardization (Yepes et al., 2016).

Small companies in the construction sector (Hartono et al., 2019) have the characteristic of being more disposed to innovation. In the first place, this is because of their proximity to suppliers, which are sources of knowledge that can be captured. Finally, they can more easily strengthen their organizational learning (Ni et al., 2018), without the need for an excessively institutionalized management, as a precursor of innovation processes (Wen \& Qiang, 2016).

\section{Materials and methods}

The purpose of this study is to determine the current state of investigation in knowledge management in the construction sector, from 2012 to date, complementing the paper of Castro et al. (2012). The research began with a first exploratory stage, a bibliometric study, followed by a quantitative and qualitative analysis of the scientific documents found. On the basis of this analysis, it was possible to draw conclusions about the current state of knowledge management in the construction sector.

After applying the respective criteria to update the state of the art to the current year, the selected articles were analyzed according to the criteria described in the "initial selection of papers" section. From a quantitative and qualitative perspective, based on framework by Castro et al. (2012), see Figure 2. Subsequently, the resulting publications were classified into eight aspects of the adopted model, and the contributions of the researchers are summarized in the following section.

\subsection{Preliminary approach and bibliometric search}

This first stage consisted in the search, examination and reading of articles published in scientific journals with the

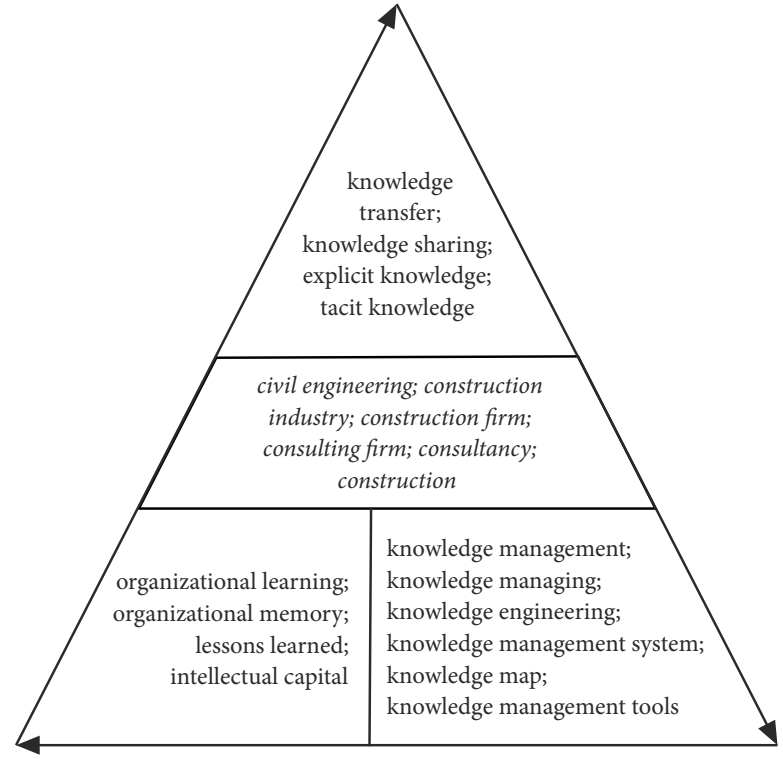

Figure 3. Search strategies (developed by the authors)

aim of the study, in order to find the key words and establish bibliometric search strategies. These strategies are shown in Figure 3. The search strategies combined four groups of keywords: (a) "knowledge transfer", "knowledge sharing", "explicit knowledge" or "tacit knowledge"; (b) "knowledge management", "knowledge managing", "knowledge engineering", "knowledge management system", "knowledge map" or "knowledge management tools"; (c) "organizational learning", "organizational memory", "lessons learned" or "intellectual capital"; (d) "civil engineering", "construction industry", "construction firm", "consulting firm", "consultancy" or "construction". The last group of keywords was used in all the search strategies in order to contextualize the search in the construction industry. The research was carried out using specialized scientific databases (Clarivate Analytics Web of Science, Scopus) and the analysis of information using the VOS viewer software, during the period from 2012 to 2020 (September 10th). On the basis of the aforementioned criteria, 2,598 articles were found.

\subsection{Initial selection}

Once the papers were identified, the initial selection considered the topic addressed and the type of document. Then, criteria were created to evaluate the relevance of the documents by topic: 1) strongly related, 2) moderately related and 3) slightly related. Items in category (3) were excluded. The next step was to eliminate duplicates and delimit them to the English language. Finally, the importance of the contribution was assessed at 3 levels: 1 ) very important, 2) moderately important and 3) slightly important. In this case, articles in class (3) were also excluded. The selection by relevance and importance was carried out jointly by the authors. Table 1 summarizes the successive stages of the selection of papers to be examined. 
Table 1. Stages for the selection of papers

\begin{tabular}{|l|c|}
\hline \multicolumn{1}{|c|}{ Stage } & $\begin{array}{c}\text { Number } \\
\text { of papers }\end{array}$ \\
\hline Bibliometric search & 2598 \\
\hline First selection: type of document and topic & 991 \\
\hline Second selection: level of relevance & 285 \\
\hline Third selection: elimination of duplicates & 224 \\
\hline Fourth selection: level of importance & 107 \\
\hline Total number of papers analyzed & 107 \\
\hline
\end{tabular}

\section{Research findings and discussion}

\subsection{Classification of papers}

In order to properly classify these 107 documents, it was necessary to establish a logical categorization of knowledge management in the construction sector. Thus, the articles were classified according to previously established factors (Figure 2). The results of this classification are presented in Table 2. The research on knowledge management has focused mainly on three factors (Table 2): use and exploitation of knowledge (24\%), knowledge transfer (23\%) and information and communication technology (22\%). As for the other five factors, the least studied were human factors (less than 3\%), as shown in Table 2.

Table 2. Classification of papers

\begin{tabular}{|l|c|}
\hline \multicolumn{1}{|c|}{ Factor } & Percentage \\
\hline Generation of Knowledge & 6.5 \\
\hline Quality of Information & 3.7 \\
\hline Knowledge Transfer & 23.4 \\
\hline Use and Exploitation of Knowledge & 24.3 \\
\hline Innovation & 6.5 \\
\hline Information and Communication Technology & 22.4 \\
\hline Knowledge Culture & 10.3 \\
\hline Human Factors & 2.8 \\
\hline Total & 100.0 \\
\hline
\end{tabular}

\subsection{Quantitative data analysis}

The data mining phase involved the quantitative analysis of the 107 documents and included information regarding:

- Research trends;

- Authors with the largest number of publications;

- Journals with the largest number of publications;

- Countries of origin of the research;

- Types of companies dealt with;

- Method used by the authors;

- Focus of the articles in terms of classification.

With the contrast of the works of Castro et al. (2012) and $\mathrm{Yu}$ and Yang (2018) updated since that date until today, the use, exploitation and transfer of knowledge remain dominant in the research, incorporating the importance that has triggered the use of information tech- nologies in the last 8 years. $74 \%$ of the articles produced relating to the topic cover the period from 2012 to 2016, with 2012 being the year with the highest number of contributions to date. On the other hand, the number of articles has decreased since 2017, indicating that the generation of knowledge and that related to human factors has declined. It seems that the current trend shows an improvement in aspects of knowledge management in the construction sector, the core basis of which is still the three pillars mentioned above. Table 3 shows the trends of the articles that have served as a basis for the classification of the works.

Table 3. Research trends per category

\begin{tabular}{|c|c|c|c|c|c|c|c|c|c|}
\hline 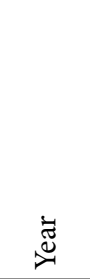 & 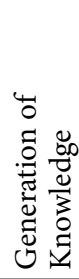 & 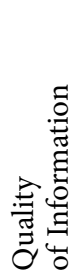 & 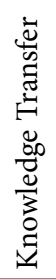 & 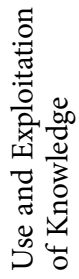 & 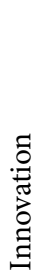 & 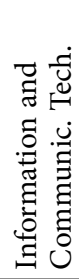 & 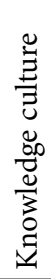 & 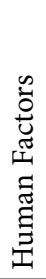 & تే \\
\hline 2012 & 3 & 1 & 3 & 7 & 2 & 4 & 2 & 1 & 23 \\
\hline 2013 & 2 & 1 & 5 & 3 & 1 & 2 & 2 & 2 & 18 \\
\hline 2014 & 1 & & 4 & 3 & & 6 & 3 & & 17 \\
\hline 2015 & & 1 & & 4 & & 3 & 2 & & 10 \\
\hline 2016 & 1 & & 3 & 3 & 1 & 2 & 1 & & 11 \\
\hline 2017 & & & 2 & 1 & & 2 & & & 5 \\
\hline 2018 & & 1 & 2 & 2 & 1 & 3 & & & 9 \\
\hline 2019 & & & 4 & & 1 & 1 & & & 6 \\
\hline $2020^{*}$ & & & 2 & 3 & 1 & 1 & 1 & & 8 \\
\hline Total & 7 & 4 & 25 & 26 & 7 & 24 & 11 & 3 & 107 \\
\hline
\end{tabular}

Note: ${ }^{\star}$ Until September $10^{\text {th }}$

The results show there was no a single researcher in a predominant position. There is a group of authors with four and three articles each respectively: on the one hand, Chen and Ng. On the other hand, Abdul-Rahman et al. As for the journals, those with more than four publications are listed in Table 4, along with their impact factors for 2020 according to the Journal Citation Reports. The Journal of Management in Engineering should be highlighted, with 15 articles ( $14 \%$ of the total).

The country of origin of the studies was assigned according to the institution where the main author of the article was located. The study shows that Asia (47\%) was the main producer of scientific articles on this matter, followed by America (27\%) and Europe (14\%). China had the largest scientific production (26\%), followed by the USA (22\%).

In addition, $12 \%$ of the research focused on companies in general, while $82 \%$ focused on construction companies and $6 \%$ on consulting firms. In regards to the research method or technique employed, $1 \%$ used case studies, $49 \%$ surveys, $25 \%$ interviews and $25 \%$ of the papers were classified in the category of other methods used. 
Table 4. Journals with most publications

\begin{tabular}{|l|c|c|c|}
\hline \multicolumn{1}{|c|}{ Journals } & Impact according to JCR (2020) & Number of articles & Percentage \\
\hline Journal of Management in Engineering & 1.255 & 15 & 14.0 \\
\hline Journal of Construction Engineering and Management & 1.039 & 14 & 13.1 \\
\hline Engineering Construction and Architectural Management & 0.682 & 12 & 11.2 \\
\hline Construction Innovation & 0.595 & 8 & 8.4 \\
\hline Automation in Construction & 1.69 & 5 & 7.5 \\
\hline Construction Management and Economics & 0.866 & 4.7 \\
\hline Expert Systems with Applications & 1.494 & 40 & 3.7 \\
\hline Others & Various & 47.4 \\
\hline
\end{tabular}

The analysis of the bibliography, combined with the contrast of the work of Castro et al. (2012) and Yu and Yang (2018) on the state of knowledge management, produced useful results. For example, the evolution of research in this field. Beginning in the first stage with a trend of knowledge generation and acquisition. Then, in a second stage, with a focus on ontology, tacit knowledge and knowledge sharing. Finally, to the application of information technologies and Big Data.

The approach of this research, based on the eight criteria described above, sheds light on the need for integration of ICT, human relations and strategic management. In addition to finding out how trends are behaving in the environment of developed countries. For example, the increase of research in Asian countries. This is with the intention of further studies of successful models applicable to Western countries.

\section{Findings for future research}

By studying the main topics in the period 2012 to 2020 it is possible to synthesize the recommendations of the authors and determine the orientation of future research on knowledge management in construction. In addition, emphasis is placed on the three most important topics, such as: Information Technologies, the use and transfer of knowledge.

Knowledge management in the construction sector is based on an integrated methodology between information technologies and social techniques. The use of big data technology is imminent in the entire economic field. Moreover, the technical approach will include more social elements, in order to improve knowledge management in the sector.

According to Yu and Yang (2018), Big data technologies are expected to be widely used in every stage of knowledge management in the construction industry. From acquisition, live capture, mining, discovery, generation and mapping. Those Big Data technologies are: RFID, distributed cache and distributed database based on MPP. In addition, research on application of big data technologies needs to integrate mature information technologies, such as semantic web supported by ontologies.

From this study, a positive trend of knowledge management towards IT and Big Data is supported. In addi- tion, another research direction is the correlation between the adoption and implementation of BIM and the complex socio-technical issues in organizations. Knowledge transfer is influenced, depending on the motivation and obligation with the adoption of such technology. On the other hand, resistance behaviors to BIM implementation during the post-adoption phase in construction projects are a future line of research.

According to Yu and Yang (2018), knowledge sharing and transfer research should take place in the social network context. Social network analysis, represented in terms of behavior, structure and relationship, are the defining factors of the knowledge sharing mechanism. Both social factors and social psychology explain the attitude and intention of personnel to share knowledge. These social components are culture, trust and environment. Therefore, interactive knowledge activities and social psychology are other parameters to be studied in depth.

Finally, the knowledge absorption and transfer capacity, both in interdisciplinary and interorganizational project teams, are other trends to be explored.

\section{Conclusions}

As noted in the "Introduction" section, the paper addresses the following research questions: what has been studied in the period from 2012 to 2020 in relation to knowledge management in construction, and what are possible future research directions? Based on the evidence gathered by the authors through a literature review of 107 articles published in the period from 2012 to 2020, the authors obtained the research framework in terms of eight proposed factors of knowledge management, and predicted the potential research directions in the future to expand the research framework.

In the period from 1981 to 2012, research on knowledge management in the construction sector mainly concentrated on the generation, transfer, and use and exploitation of knowledge, but it was really from the year 2000 onwards that it became a relevant factor to be studied. In this research, we continue research of Castro et al. (2012), which was concluded in 2012 and which has been updated to September 2020. On the other hand, we contrasted it with the work of Yu and Yang (2018) in which the evolution of knowledge transfer in the sector was analyzed in three time periods, ending in 2015. 
It was found that the most widely analyzed factors in the publications were: the use and exploitation of knowledge, knowledge transfer and information and communication technologies. In addition, five complementary facets were identified: culture, innovation, quality, knowledge generation and human factors.

In contrast with study of Castro et al. (2012), the importance of the use and exploitation of knowledge in investigations is consolidated, besides increasing the attention to the transference and technology of information, which are thus indicated as facets to investigate in the future. On the contrary, the discontinuity in research on the generation of knowledge is very noticeable, which generates the possibility of analyzing how the absorption capacity in organizations is behaving, the way it is managed and the degree of importance it is given.

The future of knowledge management is integrated by information technologies and social techniques. On the one hand, the use of big data technologies has become a reality for successful knowledge management. On the other hand, the social aspect should not be lost out of sight, because the manner in which the behavior of personnel towards technological change is managed will significantly influence the transfer of knowledge in the sector.

\section{Funding}

Grant PID2020-117056RB-I00 funded by MCIN/AEI/ $10.13039 / 501100011033$ and by "ERDF A way of making Europe".

\section{Author contributions}

This paper represents a result of teamwork. The authors jointly designed the research. V. Y. drafted the manuscript. S. L. edited and complemented the manuscript until a satisfactory version was obtained. Both authors have read and agreed to the published version of the manuscript.

\section{Disclosure statement}

The authors declare that there are no conflicts of interest regarding the publication of this article.

\section{References}

Addis, M. (2016). Tacit and explicit knowledge in construction management. Construction Management and Economics, 34(7-8), 439-445.

https://doi.org/10.1080/01446193.2016.1180416

Afolabi, A., Ojelabi, R., Fagbenle, O., \& Mosaku, T. (2017). The economics of cloud-based computing technologies in construction project delivery. International Journal of Civil Engineering and Technology (IJCIET), 8(12), 232-242.

Al-Tmeemy, S. M. H., Rahman, H. A., \& Harun, Z. (2012). Contractors' perception of the use of costs of quality system in Malaysian building construction projects. International Journal of Project Management, 30(7), 827-838.

https://doi.org/10.1016/j.ijproman.2011.12.001
Alashwal, A. M., \& Abdul-Rahman, H. (2014a). Aspects of project learning in construction: a socio-technical model. Construction Innovation, 14(2), 229-244.

https://doi.org/10.1108/CI-06-2013-0029

Alashwal, A. M., \& Abdul-Rahman, H. (2014b). Using PLS-PM to model the process of inter-project learning in construction projects. Automation in Construction, 44, 176-182.

https://doi.org/10.1016/j.autcon.2013.11.010

Alashwal, A. M., Abdul-Rahman, H., \& Radzi, J. (2016). Knowledge utilization process in highway construction projects. Journal of Management in Engineering, 32(4), 05016006. https://doi.org/10.1061/(ASCE)ME.1943-5479.0000429

Arif, M., Mohammed, A. Z., \& Gupta, A. D. (2015). Understanding knowledge sharing in the Jordanian construction industry. Construction Innovation, 15(3), 333-354.

https://doi.org/10.1108/CI-03-2014-0018

Arriagada, D. R. E., \& Alarcón, C. L. F. (2014). Knowledge management and maturation model in construction companies. Journal of Construction Engineering and Management, 140(4), B4013006.

https://doi.org/10.1061/(ASCE)CO.1943-7862.0000726

Baloian, N., \& Zurita, G. (2012). Ubiquitous mobile knowledge construction in collaborative learning environments. Sensors, 12(6), 6995-7014. https://doi.org/10.3390/s120606995

Bashouri, J., \& Duncan, G. W. (2014). A model for sharing knowledge in architectural firms. Construction Innovation, 14(2), 168-185. https://doi.org/10.1108/CI-10-2012-0057

Caldas, C. H., Elkington, R. W. T., O'Connor, J. T., \& Kim, J.Y. (2015). Development of a method to retain experiential knowledge in capital projects organizations. Journal of Management in Engineering, 31(5), 04014083. https://doi.org/10.1061/(ASCE)ME.1943-5479.0000322

Castillo, T., Alarcón, L. F., \& Pellicer, E. (2018). Finding differences among construction companies management practices and their relation to project performance. Journal of Management in Engineering, 34(3), 1-13. https://doi.org/10.1061/(asce)me.1943-5479.0000606

Castro, A. L., Yepes, V., Pellicer, E., \& Cuéllar, A. J. (2012). Knowledge management in the construction industry: State of the art and trends in research. Revista de La Construcción, 11(3), 62-73. https://doi.org/10.4067/S0718-915X2012000300006

Costa, R., Lima, C., Sarraipa, J., \& Jardim-Gonçalves, R. (2016). Facilitating knowledge sharing and reuse in building and construction domain: an ontology-based approach. Journal of Intelligent Manufacturing, 27(1), 263-282.

https://doi.org/10.1007/s10845-013-0856-5

Ding, Z., Ng, F. F., \& Wang, J. (2013). The mediation role of trust in knowledge sharing. Engineering, Construction and Architectural Management, 20(6), 604-619. https://doi.org/10.1108/ECAM-05-2011-0044

Doloi, H. (2014). Rationalizing the implementation of web-based project management systems in construction projects using PLS-SEM. Journal of Construction Engineering and Management, 140(7), 04014026. https://doi.org/10.1061/(ASCE)CO.1943-7862.0000859

Dong, C., Wang, F., Li, H., Ding, L., \& Luo, H. (2018). Knowledge dynamics-integrated map as a blueprint for system development: Applications to safety risk management in $\mathrm{Wu}-$ han metro project. Automation in Construction, 93, 112-122. https://doi.org/10.1016/j.autcon.2018.05.014

Eken, G., Bilgin, G., Dikmen, I., \& Birgonul, M. T. (2020). A lessons-learned tool for organizational learning in construction. Automation in Construction, 110, 102977. https://doi.org/10.1016/j.autcon.2019.102977 
Forcada, N., Fuertes, A., Gangolells, M., Casals, M., \& Macarulla, M. (2013). Knowledge management perceptions in construction and design companies. Automation in Construction, 29, 83-91. https://doi.org/10.1016/j.autcon.2012.09.001

Garcia, A. J., \& Mollaoglu, S. (2020). Individuals' capacities to apply transferred knowledge in AEC project teams. Journal of Construction Engineering and Management, 146(4), 04020016. https://doi.org/10.1061/(ASCE)CO.1943-7862.0001791

Goddard, J. U., Glass, J., Dainty, A., \& Nicholson, I. (2016). Implementing sustainability in small and medium-sized construction firms. Engineering, Construction and Architectural Management, 23(4), 407-427.

https://doi.org/10.1108/ECAM-01-2015-0015

Hadiwattege, C., Senaratne, S., Sandanayake, Y., \& Fernando, N. G. (2018). Academic research in emerging knowledge-based economies. Built Environment Project and Asset Management, 8(4), 415-428. https://doi.org/10.1108/BEPAM-12-2017-0134

Haron, A. T., Marshall-Ponting, A. J., Zakaria, Z., Nawi, M. N. M., Hamid, Z. A., \& Kamar, K. A. M. (2015). An industrial report on the Malaysian building information modelling (BIM) taskforce: Issues and recommendations. Malaysian Construction Research Journal, 17(2), 21-36.

Hartono, B., Sulistyo, S. R., Chai, K. H., \& Indarti, N. (2019). Knowledge management maturity and performance in a project environment: Moderating roles of firm size and project complexity. Journal of Management in Engineering, 35(6), 04019023.

https://doi.org/10.1061/(ASCE)ME.1943-5479.0000705

Hoła, B., Sawicki, M., \& Skibniewski, M. (2015). An IT model of a Knowledge Map which supports management in small and medium-sized companies using selected Polish construction enterprises as an example. Journal of Civil Engineering and Management, 21(8), 1014-1026.

https://doi.org/10.3846/13923730.2015.1030865

Jansson, G., Lundkvist, R., \& Olofsson, T. (2015). The role of experience feedback channels in the continuous development of house-building platforms. Construction Innovation, 15(2), 236-255. https://doi.org/10.1108/CI-10-2013-0042

Javernick-Will, A. (2012). Motivating knowledge sharing in engineering and construction organizations: Power of social motivations. Journal of Management in Engineering, 28(2), 193202. https://doi.org/10.1061/(ASCE)ME.1943-5479.0000076

Junyong, L. (2018). Human resource management practice, knowledge management guidance and enterprise performance. In International Conference on Computer, Civil Engineering and Management Science (pp. 72-76).

Kale, S., \& Karaman, E. A. (2012a). Benchmarking the knowledge management practices of construction firms. Journal of Civil Engineering and Management, 18(3), 335-344. https://doi.org/10.3846/13923730.2012.698910

Kale, S., \& Karaman, E. A. (2012b). A diagnostic model for assessing the knowledge management practices of construction firms. KSCE Journal of Civil Engineering, 16(4), 526-537. https://doi.org/10.1007/s12205-012-1468-X

Keung, C. C. W., \& Shen, L. Y. (2013). Measuring the networking performance for contractors in practicing construction management. Journal of Management in Engineering, 29(4), 400406. https://doi.org/10.1061/(ASCE)ME.1943-5479.0000156

Kildienè, S., Zavadskas, E. K., \& Tamošaitienè, J. (2014). Complex assessment model for advanced technology deployment. Journal of Civil Engineering and Management, 20(2), 280-290. https://doi.org/10.3846/13923730.2014.904813

Kim, S. B. (2014). Impacts of knowledge management on the organizationlal success. KSCE Journal of Civil Engineering, 18(6), 1609-1617. https://doi.org/10.1007/s12205-014-0243-6
Lindgren, J., Emmitt, S., \& Widén, K. (2018). Construction projects as mechanisms for knowledge integration. Engineering, Construction and Architectural Management, 25(11), 15161533. https://doi.org/10.1108/ECAM-02-2017-0022

Liu, F., Anumba, C. J., Jallow, A. K., \& Carrillo, P. (2019). Integrated change and knowledge management system-development and evaluation. Journal of Information Technology in Construction (ITcon), 24, 112-128.

Manley, K., \& Chen, L. (2015). Collaborative learning model of infrastructure construction: A capability perspective. Construction Innovation, 15(3), 355-377.

https://doi.org/10.1108/CI-05-2014-0031

Navarro, I. J., Penadés-Plà, V., Martínez-Muñoz, D., Rempling, R., \& Yepes, V. (2020). Life cycle sustainability assessment for multi-criteria decision making in bridge design: a review. Journal of Civil Engineering and Management, 26(7), 690-704. https://doi.org/10.3846/jcem.2020.13599

Ni, G., Cui, Q., Sang, L., Wang, W., \& Xia, D. (2018). Knowledgesharing culture, project-team interaction, and knowledgesharing performance among project members. Journal of Management in Engineering, 34(2), 04017065. https://doi.org/10.1061/(ASCE)ME.1943-5479.0000590

Nourbakhsh, M., Mohamad Zin, R., Irizarry, J., Zolfagharian, S., \& Gheisari, M. (2012). Mobile application prototype for onsite information management in construction industry. Engineering, Construction and Architectural Management, 19(5), 474-494. https://doi.org/10.1108/09699981211259577

Orsi, A., Guillén-Guillamón, I., \& Pellicer, E. (2020). Optimization of green building design processes: Case studies within the European Union. Sustainability, 12(6), 2276. https://doi.org/10.3390/su12062276

Ortiz-González, J. I., Pellicer, E., \& Molenaar, K. R. (2018). Management of time and cost contingencies in construction projects: a contractor perspective. Journal of Civil Engineering and Management, 24(3), 254-264.

https://doi.org/10.3846/jcem.2018.1643

Papadonikolaki, E. (2018). Loosely coupled systems of innovation: Aligning BIM adoption with implementation in Dutch construction. Journal of Management in Engineering, 34(6), 05018009 .

https://doi.org/10.1061/(ASCE)ME.1943-5479.0000644

Park, M., Jang, Y., Lee, H. S., Ahn, C., \& Yoon, Y. S. (2013). Application of knowledge management technologies in Korean small and medium-sized construction companies. KSCE Journal of Civil Engineering, 17(1), 22-32.

https://doi.org/10.1007/s12205-013-1607-Z

Pellicer, E., Correa, C. L., Yepes, V., \& Alarcón, L. F. (2012). Organizational improvement through standardization of the innovation process in construction firms. Engineering Management Journal, 24(2), 40-53. https://doi.org/10.1080/10429247.2012.11431935

Pellicer, E., Yepes, V., Correa, C. L., \& Alarcón, L. F. (2014). Model for systematic innovation in construction companies. Journal of Construction Engineering and Management, 140(4), B4014001. https://doi.org/10.1061/(ASCE)CO.1943-7862.0000700

Pellicer, E., Yepes, V., Correa, C., \& Martínez, G. (2011). Enhancing R\&D\&i through standardization and certification: the case of the Spanish construction industry. Revista Ingenieria de Construccion, 23(2), 112-121.

Pellicer, E., Yepes, V., Ortega, A. J., \& Carrión, A. (2017). Market demands on construction management: View from graduate students. Journal of Professional Issues in Engineering Education and Practice, 143(4), 04017005.

https://doi.org/10.1061/(ASCE)EI.1943-5541.0000334 
Qian Li, Z., Chen Tan, H., Anumba, C., \& Choy Chia, F. (2017). Development of a web-based system for managing suppliers' performance and knowledge sharing in construction project. Built Environment Project and Asset Management, 7(2), 117129. https://doi.org/10.1108/BEPAM-10-2015-0061

Schröpfer, V. L. M., Tah, J., \& Kurul, E. (2017). Mapping the knowledge flow in sustainable construction project teams using social network analysis. Engineering, Construction and Architectural Management, 24(2), 229-259.

https://doi.org/10.1108/ECAM-08-2015-0124

Senaratne, S., Jin, X. H., \& Balasuriya, K. (2017). Exploring the role of networks in disseminating construction project knowledge through case studies. Engineering, Construction and Architectural Management, 24(6), 1281-1293.

https://doi.org/10.1108/ECAM-10-2014-0125

Sheriff, A., Bouchlaghem, D., El-Hamalawi, A., \& Yeomans, S. (2012). Information management in UK-based architecture and engineering organizations: drivers, constraining factors, and barriers. Journal of Management in Engineering, 28(2), 170-180. https://doi.org/10.1061/(ASCE)ME.1943-5479.0000085

Skibniewski, M. J., \& Zavadskas, E. K. (2013). Technology development in construction: A continuum from distant past into the future. Journal of Civil Engineering and Management, 19(1), 136-147. https://doi.org/10.3846/13923730.2012.756060

Sujan, S. F., Wynford Jones, S., Kiviniemi, A., Wheatcroft, J. M., \& Mwiya, B. (2020). Holistically assessing collaborative culture in the AEC industry. Journal of Information Technology in Construction (ITcon), 25, 272-286.

https://doi.org/10.36680/j.itcon.2020.016

Sun, J., Ren, X., \& Anumba, C. J. (2019). Analysis of knowledge-transfer mechanisms in construction project cooperation networks. Journal of Management in Engineering, 35(2), 04018061.

https://doi.org/10.1061/(ASCE)ME.1943-5479.0000663

Tan, H. C., Carrillo, P. M., \& Anumba, C. J. (2012). Case study of knowledge management implementation in a medium-sized construction sector firm. Journal of Management in Engineering, 28(3), 338-347.

https://doi.org/10.1061/(ASCE)ME.1943-5479.0000109

Vennström, A., \& Eriksson, P. E. (2010). Client perceived barriers to change of the construction process. Construction Innovation, 10(2), 126-137. https://doi.org/10.1108/14714171011037156

Villarreal, K. L., Pellicer, E., \& Rodriguez, S. G. (2017). Performance indicators for developer and homebuilder Mexican companies: A Delphi study. Revista de La Construcción, 16(1), 133-144. https://doi.org/10.7764/RDLC.16.1.133

Walker, D. H. T. (2016). Reflecting on 10 years of focus on innovation, organisational learning and knowledge management literature in a construction project management context. Construction Innovation, 16(2), 114-126.

https://doi.org/10.1108/CI-12-2015-0066

Wang, G., Wang, P., Cao, D., \& Luo, X. (2020). Predicting behavioural resistance to BIM implementation in construction projects: an empirical study integrating technology acceptance model and equity theory. Journal of Civil Engineering and Management, 26(7), 651-665. https://doi.org/10.3846/jcem.2020.12325

Wang, H., \& Wang, S. (2016). Application of ontology modularization to human-web interface design for knowledge sharing. Expert Systems with Applications, 46, 122-128.

https://doi.org/10.1016/j.eswa.2015.10.027
Wen, Q., \& Qiang, M. (2016). Coordination and knowledge sharing in construction project-based organization: a longitudinal structural equation model analysis. Automation in Construction, 72, 309-320.

https://doi.org/10.1016/j.autcon.2016.06.002

Wu, G. D. (2013). Knowledge collaborative incentive based on inter-organizational cooperative innovation of project-based supply chain. Journal of Industrial Engineering and Management, 6(4), 1065-1081. https://doi.org/10.3926/jiem.772

Yang, J., \& Cheng, Q. (2020). The impact of organisational resilience on construction project success: evidence from largescale construction in China. Journal of Civil Engineering and Management, 26(8), 775-788.

https://doi.org/10.3846/jcem.2020.13796

Yang, J.-B., Yu, W.-D., Tseng, J. C. R., Chang, C. S., Chang, P. L., $\& \mathrm{Wu}$, J. W. (2014). Benefit analysis of knowledge management system for engineering consulting firms. Journal of Management in Engineering, 30(4), 05014005. https://doi.org/10.1061/(ASCE)ME.1943-5479.0000221

Yap, J. B. H., \& Lock, A. (2017). Analysing the benefits, techniques, tools and challenges of knowledge management practices in the Malaysian construction SMEs. Journal of Engineering, Design and Technology, 15(6), 803-825. https://doi.org/10.1108/JEDT-07-2017-0067

Yepes, V., Pellicer, E., Alarcón, L. F., \& Correa, C. L. (2016). Creative innovation in Spanish construction firms. Journal of Professional Issues in Engineering Education and Practice, 142(1), 04015006.

https://doi.org/10.1061/(ASCE)EI.1943-5541.0000251

Yu, D., \& Yang, J. (2018). Knowledge management research in the construction industry: a review. Journal of the Knowledge Economy, 9(3), 782-803. https://doi.org/10.1007/s13132-016-0375-7

Zhai, X., Liu, A. M. M., \& Fellows, R. (2014). Role of human resource practices in enhancing organizational learning in Chinese construction organizations. Journal of Management in Engineering, 30(2), 194-204. https://doi.org/10.1061/(ASCE)ME.1943-5479.0000207

Zhang, L., \& He, J. (2016). Critical factors affecting tacit-knowledge sharing within the integrated project team. Journal of Management in Engineering, 32(2), 04015045. https://doi.org/10.1061/(ASCE)ME.1943-5479.0000402

Zhang, P., \& Ng, F. F. (2012a). Analysis of knowledge sharing behaviour in construction teams in Hong Kong. Construction Management and Economics, 30(7), 557-574. https://doi.org/10.1080/01446193.2012.669838

Zhang, P., \& Ng, F. F. (2012b). Attitude toward knowledge sharing in construction teams. Industrial Management \& Data Systems, 112(9), 1326-1347.

https://doi.org/10.1108/02635571211278956

Zhang, P., \& Ng, F. F. (2013). Explaining knowledge-sharing intention in construction teams in Hong Kong. Journal of Construction Engineering and Management, 139(3), 280-293. https://doi.org/10.1061/(ASCE)CO.1943-7862.0000607

Zhu, L., \& Cheung, S. O. (2017). Harvesting competitiveness through building organizational innovation capacity. Journal of Management in Engineering, 33(5), 04017020. https://doi.org/10.1061/(ASCE)ME.1943-5479.0000534 